\title{
Influence of Micro Cold Pressing on Surface Wear ability of Mold Steel
}

\author{
Jing Wang ${ }^{1,2, a}$, Jie Zhou ${ }^{1, b}, *$ and Tiansheng Zhao ${ }^{1, \mathrm{c}}$ \\ ${ }^{1}$ School of Materials Science and Engineering, Chongqing University, Chongqing \\ 400044, China \\ ${ }^{2}$ Department of automotive engineering, Chongqing Technology and Business \\ Institute, Chongqing 400044, China \\ awangjing-0113@163.com, ${ }^{b}$ zhoujie@cqu.edu.cn, ${ }^{c} 1040728410 @ q q . c o m$ \\ * Corresponding Author: Jie Zhou
}

\begin{abstract}
Both traditional grinding and micro cold pressing are conducted to compare the micro surface morphologies of cold work mold steel specimen. Surface roughness, hardness and surface morphologies are analyzed under varying feeds of ball end cutter in $Y$ direction and $Z$ direction in MCP. The friction coefficients and wear rates of two types of specimen under oil lubrication are obtained through friction and wear test. After micro cold pressing, hardness increases from 0.11 to 0.099 , with surface roughness reduced from 5.496 $\mu \mathrm{mto} 1.871 \mu \mathrm{m}$ and wear rate reduced from $0.0506 \mu \mathrm{m}$ to $0.0153 \mu \mathrm{m}$ (Wear rate is measured in $Z$ direction). The study shows that during micro cold pressing the ball end cutter flattens wear scar, which reduces surface roughness. Surface roughness is related to DY and DZ. Under fixed DZ, reduction in DY leads to an increase in flatness of specimen surface. Since work hardening takes place during micro cold pressing, surface hardness of specimen has improved with the greatest increment at 169.6HV.Grooved surface morphology is obtained by micro cold pressing. The depth of groove is related to DY and DZ. When DZ is fixed, depth of groove is smaller when DY is $0.05 \mathrm{~mm}$ than that when DY is $0.1 \mathrm{~mm}$. Under fixed DY, the depth of groove increases with the increase of DZ. Surface quality (including surface roughness, roughness and surface morphology) affects friction coefficient and wear rate. Reasonable surface quality not only decreases friction coefficient but also decreases wear rate. Friction coefficient can be reduced by $10 \%$ while wear rate can be reduced by $69.76 \%$.
\end{abstract}

Keywords: Micro cold pressing, surface morphology, friction coefficient, wear loss.

\section{Introduction}

Manufacturing, which represents comprehensive national power and technology level, is based on the development of mold industry. The value of products produced with dies are worth is dozens of times higher than cost of dies. With the intensifying competition in automotive industry, it is predicted update of automotives during the twelfth five-year plan will push forward an automotive die market worth 12 to 16 billion [1]. Therefore, the die industry, which directly affects the competitiveness of automotive products, has displayed its great prospect. In the friction pair comprised of die, the workpieces and their interface, the friction characteristics have a critical effect on product quality, productivity, die capacity and service life. There has been an urgent need for decrease in frictional wear so as to improve product quality, productivity and reduce manufacturing cost [2-4]. All friction surfaces are consisted of micro peaks and valleys. The geometric characteristics play a significant role in frictional wear and lubrication in mixed lubrication and dry friction. The structure of metal surface varies with different processing conditions. There is a great difference between the mechanical properties between surface material and base material. The strengthening degree, 
micro toughness and residual stress of surface metal has an important effect on frictional wear [5]. Factors influencing die wear ability include die material, lubrication condition, surface morphology, surface finish, hardness and working condition, etc.

Do not number your paper: All manuscripts must be in English, also the table and figure texts, otherwise we cannot publish your paper. Please keep a second copy of your manuscript in your office. When receiving the paper, we assume that the corresponding authors grant us the copyright to use the paper for the book or journal in question.

\section{Friction and Wear Test}

\subsection{Specimen Material and Specification}

Cold work mold steel $\mathrm{Cr} 12 \mathrm{MoV}$ is selected as specimen material, whose harness increases to HV700 after quenching. Traditional grinding is applied, with axial feed at 5 $\mathrm{mm} / \mathrm{s}$ and rotational speed of grinding wheel at $1000 \mathrm{n} / \mathrm{min}$. The surface roughness $\mathrm{Sa}$ is around $5.5 \mu \mathrm{m}$. Micro cold pressing is conducted with CNC machine and specimens with size of $30 \mathrm{~mm} * 10 \mathrm{~mm} * 10 \mathrm{~mm}$ are obtained by cutting.

\subsection{Specimen Preparation Technique}

Two types of specimens are used in the experiment. All of the material are processed by grinding, but some of the specimens after grinding are further processed by micro cold pressing (see Figure 1). During micro cold pressing process, the specimen is oil lubricated and a ball end cutter with a diameter of $10 \mathrm{~mm}$. Feed in $\mathrm{Y}$ direction and $\mathrm{Z}$ direction are variable with fixed feed of $800 \mathrm{n} / \mathrm{min}$ in $\mathrm{X}$ direction. Feed in $\mathrm{Y}$ direction and $\mathrm{Z}$ direction are denoted as DY and DZ respectively. Specimen number, DY and DZ are displayed in Table 1.

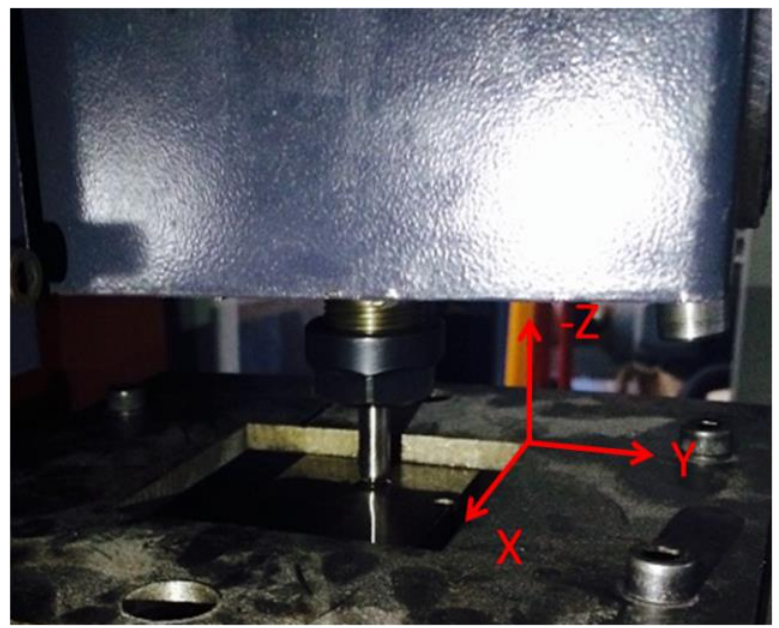

Figure 1. Surface Treatment of Specimen 
Table 1. Specimen Number

\begin{tabular}{ccc}
\hline Number & $\mathrm{D}_{\mathrm{Y}}(\mathrm{mm})$ & $\mathrm{D}_{\mathrm{Z}}(\mathrm{mm})$ \\
\hline NO.0 & 0 & 0 \\
NO.1 & 0.05 & 0.1 \\
NO.2 & 0.05 & 0.2 \\
NO.3 & 0.05 & 0.3 \\
NO.4 & 0.05 & 0.2 (twice feed) \\
NO.5 & 0.05 & 0.3 (three times feed) \\
NO.6 & 0.1 & 0.1 \\
NO.7 & 0.1 & 0.3 \\
NO.8 & 0.1 & 0.2 (twice feed) \\
NO.9 & 0.1 & 0.3 (three times feed) \\
\hline
\end{tabular}

\subsection{Friction and Wear Test}

The friction and wear test is carried out on RTEC highly-integrated multifunctional friction and wear tester. The tester can be used to study various materials, film membrane, coverage, modified layers, bulk materials, solid or liquid lubricating layer, mechanical characteristics, frictional characteristics of lubricating oil and lubricant and actual working condition. It can switch between different test modes, like spinning ball disk or pin disk mode, high-speed reciprocating mode and Timken ring block mode. It measures frictional force, loading force, online wear depth and online three-dimensional morphology (wear depth, width, volume, roughness and etc.)in the meantime. Sensers adopt an interchangeable modular organization, which enables a wide-range test ranging from low load to high load. During a friction and wear test, the specimen platform moves in $\mathrm{X}$ direction and $\mathrm{Y}$ direction and spins around $\mathrm{Z}$ axis, which realizes a compound motion.

Two specimens are needed in the test. The upper specimen is a pin made of GCr15 with a diameter of $6 \mathrm{~mm}$ and harness of HRC 65 . The lower specimen is made according to No.0 to No.9 in Table 1. Each time the motor spindle rotates, the upper specimen and lower specimen move in a straight line relative to each other twice. The frequency is $8 \mathrm{HZ}$ under a loading force of $150 \mathrm{~N}$ and the friction lasts for 15 minutes. Oil lubrication is applied between the two specimens, which mean plenty lubricating oil is applied to the friction surface of lower specimen during the test. The lubricating oil used is Hasitai No.5 engine oil made in Shanghai, China. Figure 2 shows the procedure of the test.

\section{Results and Analysis}

\subsection{Effects of Micro Cold Pressing On Surface Roughness and Hardness}

Table 2 displays surface roughness and hardness of specimens. Results demonstrate that surface roughness of specimens decreases remarkably after micro cold pressing while hardness increases. When micro cold pressing is applied, ball end cutter flattens wear scars caused by grinding on specimen surface by cutting peaks and filling valleys. On the other hand, hardness increases mainly because work hardening during micro cold pressing. Plastic forming of surface structure leads to compression of lattice, enhancement of micro harness and strengthening of surface [6]. 
Table 2. Surface Roughness and Hardness of Specimen Surface

\begin{tabular}{ccccccccccc}
\hline $\begin{array}{c}\text { Specimen } \\
\text { number }\end{array}$ & NO.0 & NO.1 & NO.2 & NO.3 & NO.4 & NO.5 & NO.6 & NO.7 & NO.8 & NO.9 \\
\hline $\begin{array}{c}\text { Surface } \\
\text { roughness } \\
(\mu \mathrm{m})\end{array}$ & 5.496 & 2.228 & 2.226 & 1.871 & 2.844 & 2.61 & 2.899 & 2.958 & 3.7 & 4.976 \\
Hardness $(H V)$ & 704 & 871.7 & 785.6 & 824.6 & 805.4 & 810.5 & 815.9 & 757.4 & 847.5 & 873.6 \\
\hline
\end{tabular}

Figure 3 illustrates the relation between surface roughness and feed. Under fixed DZ, surface roughness is smaller when DY is $0.05 \mu \mathrm{m}$ than that when DY is $0.1 \mu \mathrm{m}$. It indicates that smaller DY results in flatter specimen surface. The smaller DY is, the more times the ball end cutter has to move in the same zone, which reduces the appearance of peaks and valleys on the specimen surface. When DY and DZ are the same, one time feed in $\mathrm{Z}$ direction results in smaller surface roughness compared to many times feed. Therefore, many times feed is adverse for obtaining small surface roughness. Many times feed means applying micro cold pressing to the same zone several times, butrepeated micro cold pressing causes wrinkling on the specimen surface. A reasonable control of DY, DZ and feed times can effectively improve surface quality of specimen.

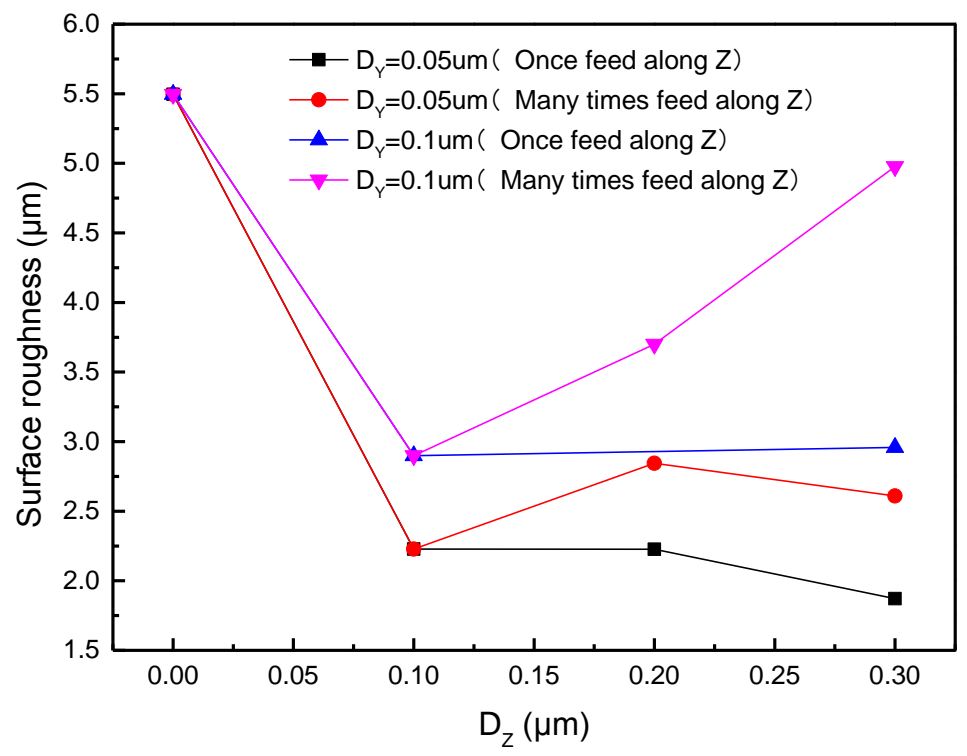

Figure 3. Relation between Surface Roughness and Feed

Figure 4 shows the matrix structure and Figure 5 show the sectional microstructure of each specimen. The comparison between matrix structure and sectional microstructure indicates that grinding does not contribute to significant structural changes on specimen surface while micro cold pressing results in remarkable structural changes on the surface. After micro cold pressing, slip occurs frequently compared to the original matrix structure. Slip is the main deformation mechanism during micro cold pressing. The more frequently slip occurs, the more distinct work hardening is and the thicker the work-hardening layer is(see Figure 4 and Figure 5). Work hardening is the result of the increasing resistance of dislocation movement with the accumulation of deformation [6]. The thickness of work-hardening layer has a direct impact on the plastic deformation on the surface [7]. The greater the deformation is, the thicker the work-hardening layer is. Under fixed DY, the thickness of work-hardening layer 
increases with the increase of DZ. The work-hardening layer of No.3 is thicker than that of No.2. When DY and DZ are the same, many times feed in Z direction leads to a thicker work-hardening layer than once feed. The work-hardening layer of No.4 is thicker than that of No.2 while the layer of No.5 is thicker than that of No.3.

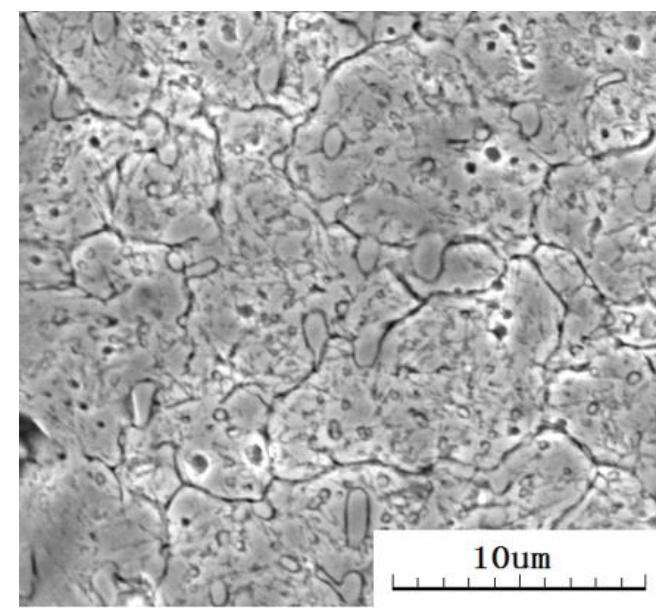

Figure 4. Matrixstructure

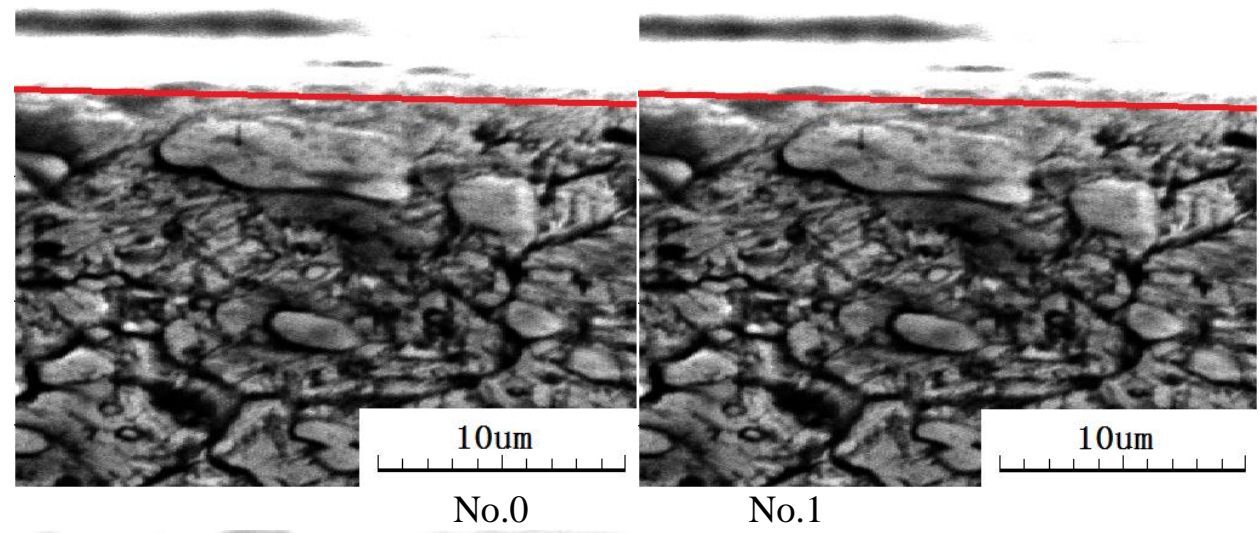

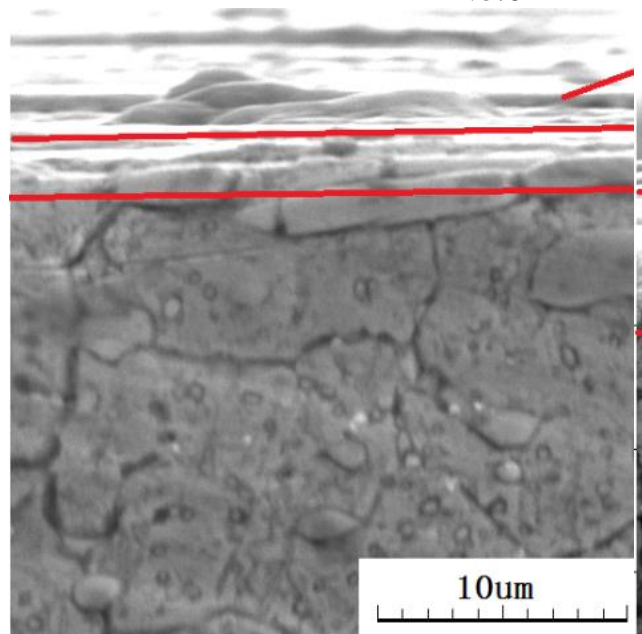

No. 2
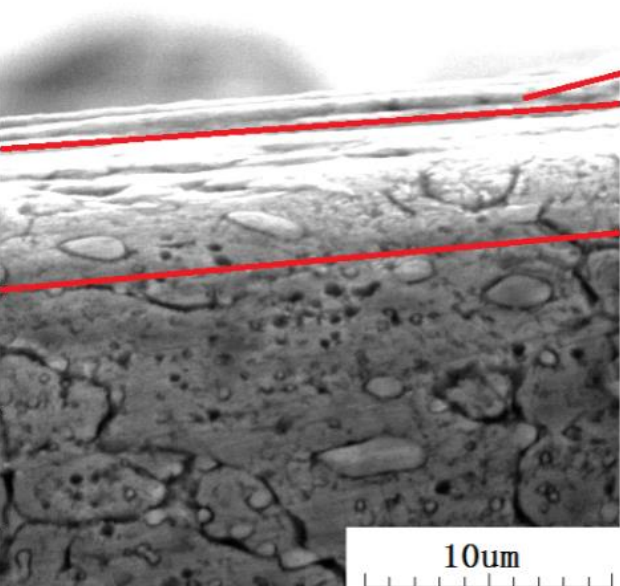

No.3 


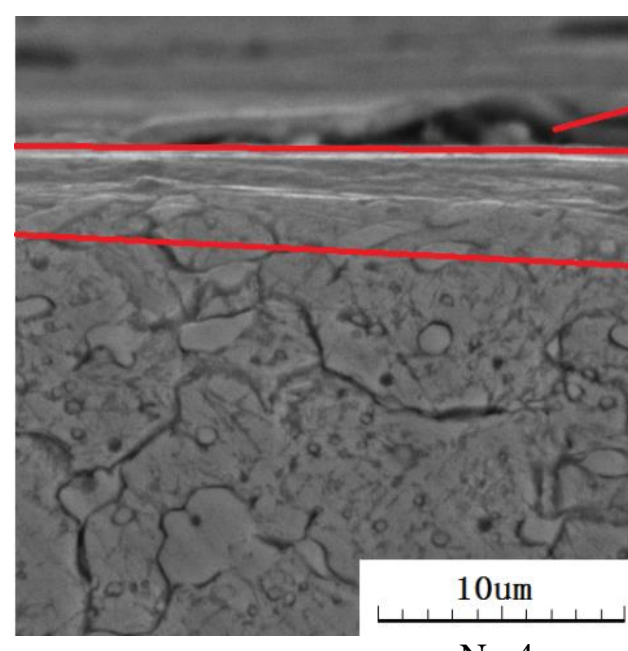

No.4

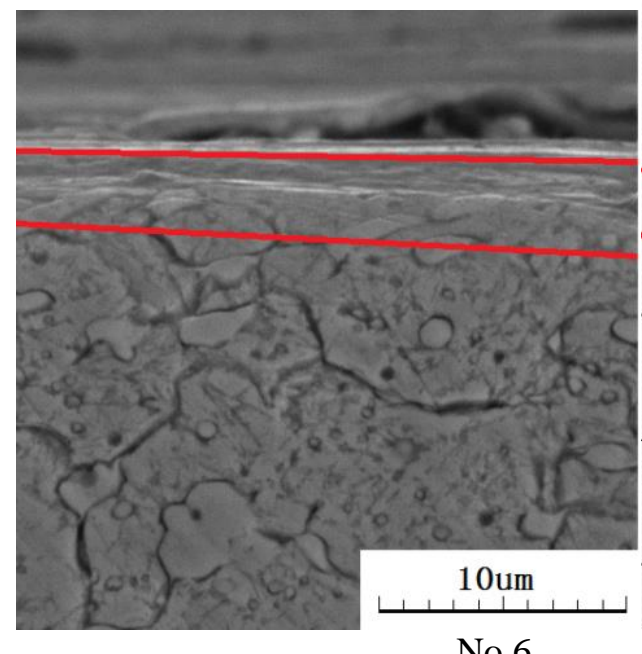

No.6

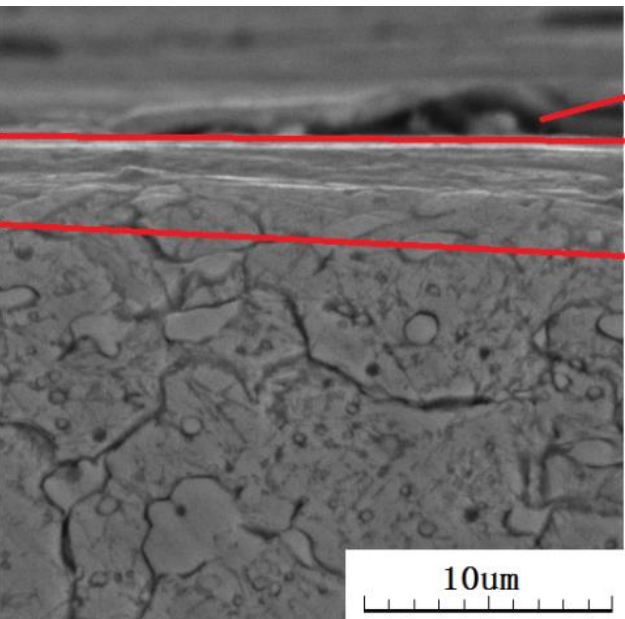

No.5

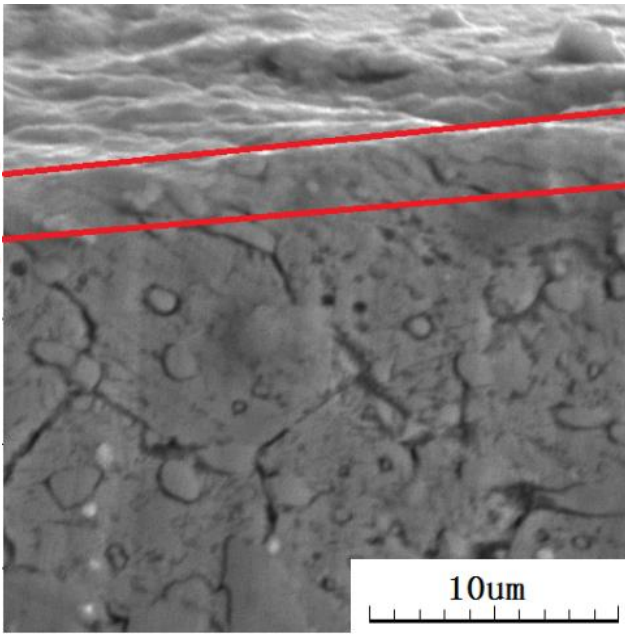

No.7

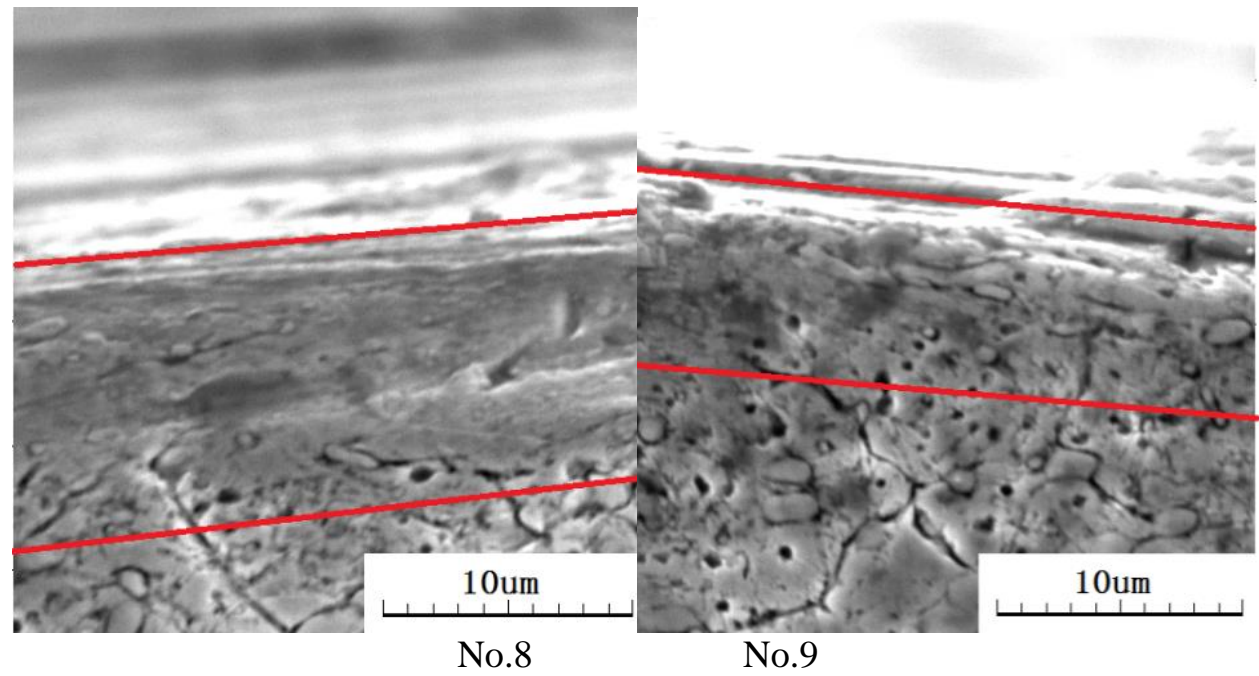

Figure 5. Sectional Microstructure of Each Specimen 


\subsection{Influence of Micro Cold Pressing On Surface Morphology of Specimen}

Table 3 displays surface morphology of each specimen. Figure 6 illustrates sectional height of specimen. The curve of sectional height is obtained using a microscope whose magnification is 10 . To precisely portrait surface morphology of specimens after micro cold pressing, filtering is applied to the sectional curve in order to get the 2dimensional curve of surface morphology. To represent surface morphology quantitively, sectional height amplitude, which is the difference between maximum and minimum (calculated as $\mathrm{d} 0$ - $\mathrm{d} 9$ ), is adopted to characterize the image. Table 4 represents the sectional height amplitude of each specimen. The grooved scar, which is cause by ball end cutter during micro cold pressing, is distinctly shown in Figure 6. Compared with wear scar of No.0, the depth of wear scar is much shallower after micro cold pressing. Figure 7 demonstrates the relation between sectional height amplitude and feed. Figure 6 and Figure 7 illustrates that the depth and distribution of grooved scar is relative to the magnitude of DY and DZ. To be specific, the depth of wear scar is smaller when DY is 0.05 than that when DY is 0.1. With fixed DY, the depth of scar increases with the increase of DZ. Therefore, reasonable control of DY and DZ will lead to a uniform distribution of grooved scar across the surface.

Table 3. Surface Morphology of Specimens

Specimen
number



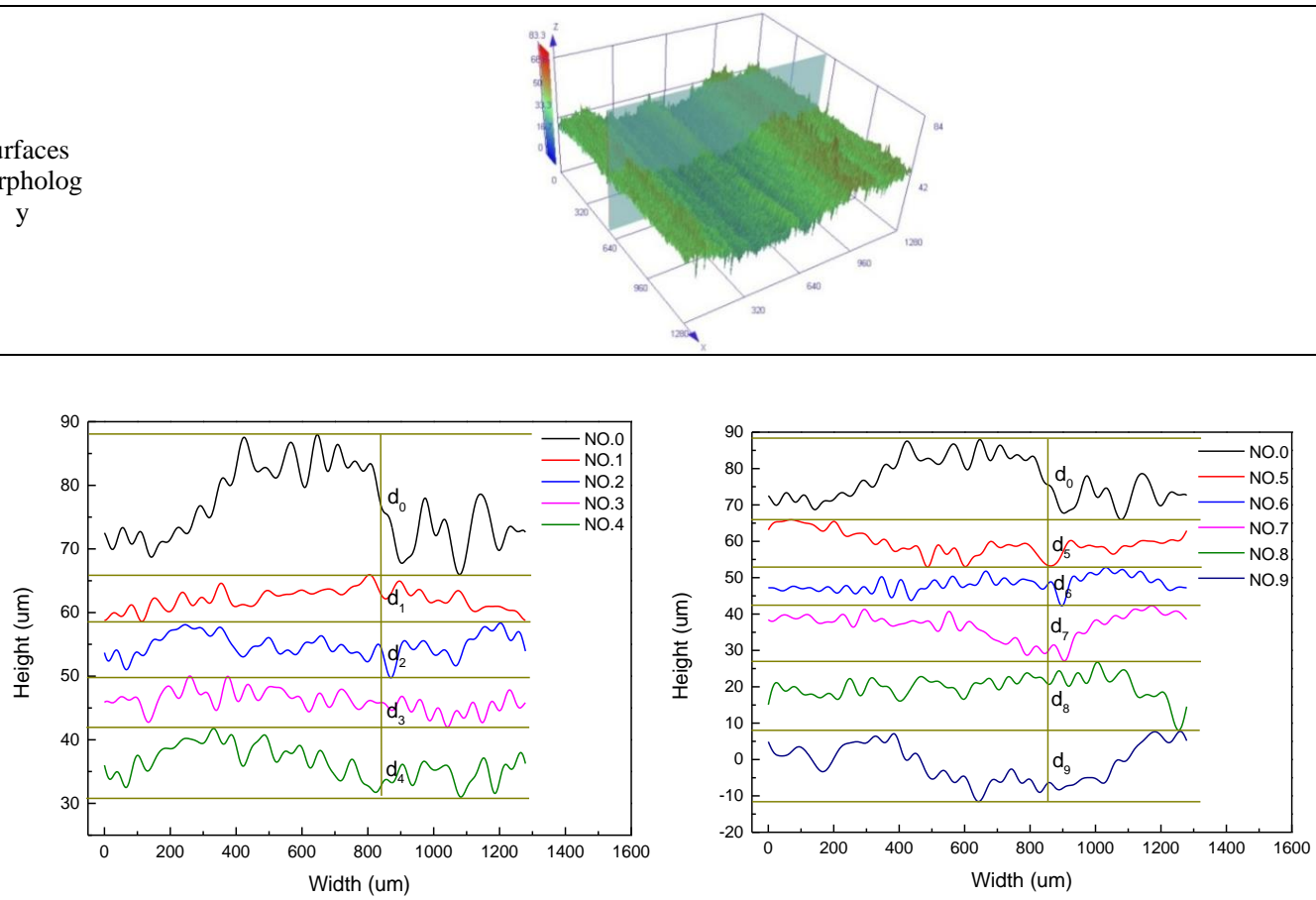

Figure 6. Sectional Heights of Specimens
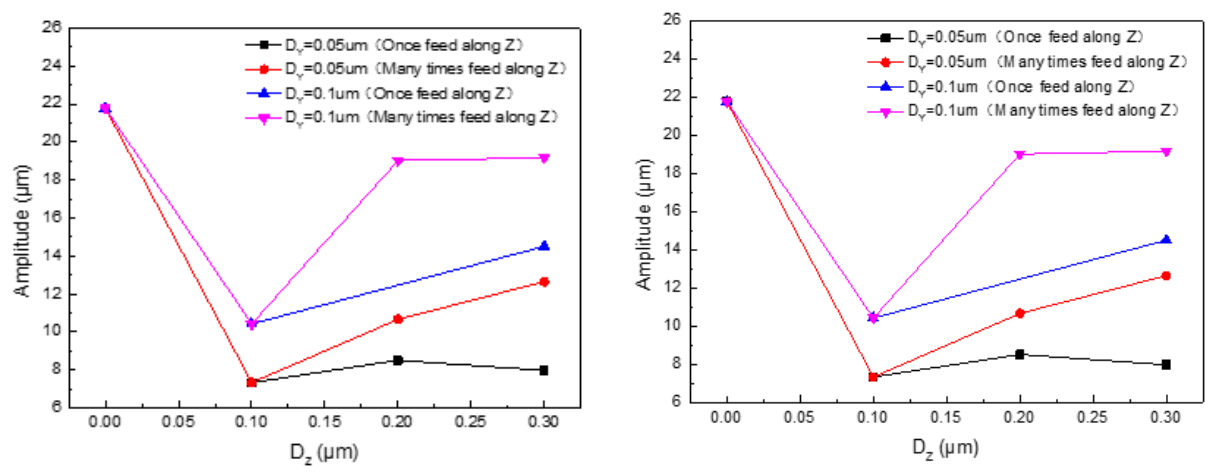

Figure 7. The Amplitude and DZ

Table 4. The Sectional Height Amplitude

\begin{tabular}{ccccccccccc}
\hline Nomuber & $\mathrm{d}_{0}$ & $\mathrm{~d}_{1}$ & $\mathrm{~d}_{2}$ & $\mathrm{~d}_{3}$ & $\mathrm{~d}_{4}$ & $\mathrm{~d}_{5}$ & $\mathrm{~d}_{6}$ & $\mathrm{~d}_{7}$ & $\mathrm{~d}_{8}$ & $\mathrm{~d}_{9}$ \\
\hline $\begin{array}{l}\text { sectional height } \\
\text { amplitude }(\mu \mathrm{m})\end{array}$ & 21.77 & 7.34 & 10.67 & 7.98 & 8.52 & 12.65 & 10.43 & 14.51 & 19.02 & 19.17 \\
\hline
\end{tabular}




\subsection{Influence of Micro Cold Pressing On Friction Coefficient on Specimen Surface}

Figure 8 shows the friction coefficient curve of specimens. Friction coefficient is much bigger at the beginning of friction test than in a steady state, because at the instant of beginning the friction is close to static friction whose coefficient is far bigger than kinetic friction coefficient. All specimens after micro cold pressing has a smaller friction coefficient than specimen No.0 without micro cold pressing. In addition, the friction coefficient curve of specimens No.1 to No.9 is smoother than that of specimen No.0. It is easier for specimens after micro cold pressing to get into a static stage. While it takes 320s for specimen No.0, it takes only 160s for No.4 to get into a static stage, which saves as much as half time of the former. Figure 9 illustrates the relation between friction coefficient and sectional height amplitude. With the increase of sectional height amplitude, friction coefficient decreases first and then increases again. There exists an optimum value on the curve.

Three reasons contribute to the phenomenon above. Firstly, surface roughness of specimens decrease a lot after micro cold pressing. Secondly, surface hardness rises at certain degree after micro cold pressing. Within certain limits, the decrease of surface roughness directly reduces the resistance to slip. The increase of hardness decreases plastic deformation during friction and further decreases frictional resistance to slip[8]. Thirdly, a reasonable depth of grooved scar forms surface texture which can store lubricant and accumulate tiny wear particles. Thus, abrasive wear and furrow are effectively prevented. With lubricant oil, surface texture is more likely to form hydrodynamic lubrication which can improve bearing capacity and frictional characteristics of the surface [9-11]. Under oil lubrication or mixed lubrication, micro holes or micro grooved texture can serve as micro hydrodynamic bearings so as to exert additional hydrodynamic pressure. Under starved lubrication, as the friction continues, lubricant oil stored in grooves can form oil film for the friction pair and decrease friction coefficient [12-13].

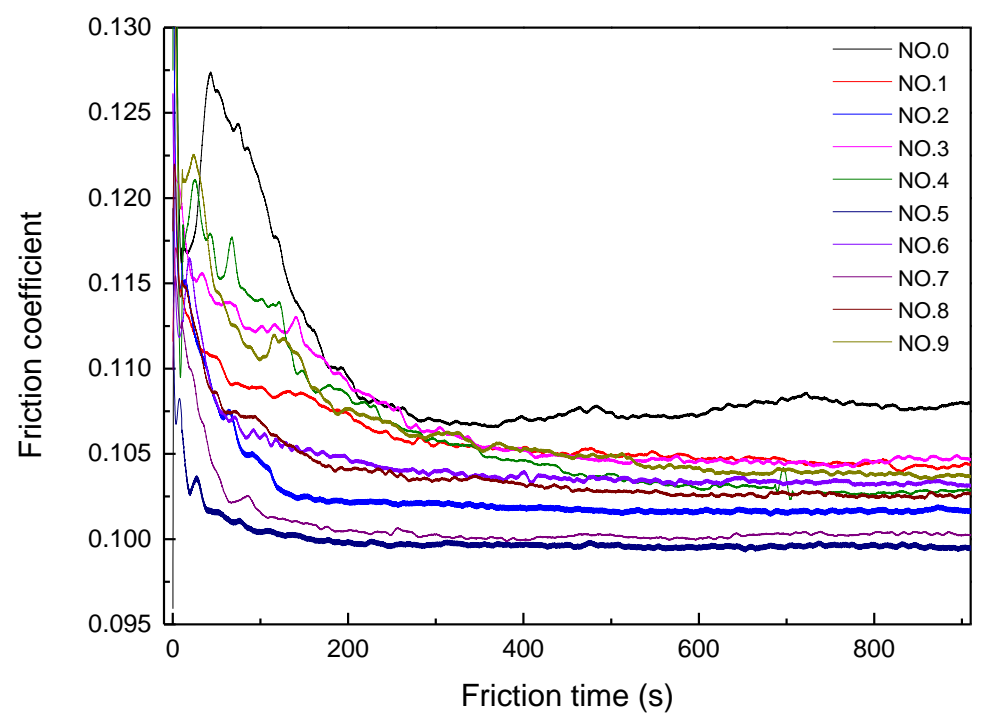

Figure 8. Friction Coefficient Curves of Specimens 


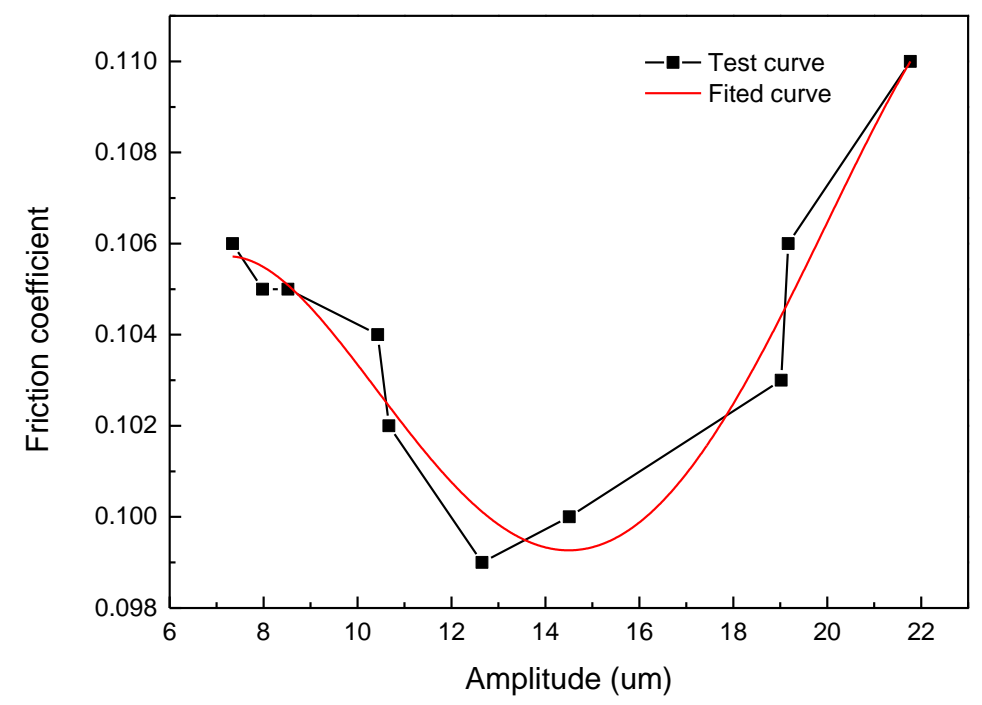

Figure 9. The Relation between Friction Coefficient and Sectional Height Amplitude

\subsection{Influence of Micro Cold Pressing On Surface Wear Rate}

In this work, wear rate is represented by changes in $\mathrm{Z}$ coordinate, denoted by $\Delta Z_{\mathrm{n}}$ (displacement vertical to the friction surface) where $\mathrm{n}$ denotes specimen number. Wear rate decline $\Delta$, which represents the difference of wear rate before and after micro cold pressing.

$$
\Delta=\frac{\Delta Z_{0}-\Delta Z_{\mathrm{n}}}{\Delta Z_{0}} \times 100 \%
$$

Table 5 shows the wear rate and wear rate decline of specimens.

Table 5. Wear Rate and Wear Rate Decline of Specimens

\begin{tabular}{|c|c|c|c|c|c|c|c|c|c|c|}
\hline $\begin{array}{l}\text { Specimen } \\
\text { number }\end{array}$ & 0 & 1 & 2 & 3 & 4 & 5 & 6 & 7 & 8 & 9 \\
\hline$\Delta Z_{\mathrm{n}}(\mu \mathrm{m})$ & 0.0506 & 0.0343 & 0.0447 & 0.0385 & 0.0426 & 0.0153 & 0.0317 & 0.0792 & 0.0414 & 0.0959 \\
\hline$\Delta$ & 0 & $32.21 \%$ & $11.66 \%$ & $23.91 \%$ & $15.81 \%$ & $69.76 \%$ & $37.35 \%$ & $-56.52 \%$ & $18.18 \%$ & $-\overline{89.53 \%}$ \\
\hline
\end{tabular}

Figure 10 illustrates the relation between wear rate and feed in $\mathrm{Z}$ direction. Compared with specimen without micro cold pressing, most of specimens get a decrease in wear rate but the opposite condition also exists. Micro cold pressing results in work hardening on the specimen surface and smoothens the surface. Moreover, residual stress on specimen surface also changes and mainly exists in the form of compressive stress. Therefore, micro cold pressing decrease friction coefficient and wear rate to a certain degree but not all micro cold pressing lead to the decrease of wear rate. When DY is $0.1 \mathrm{~mm}$ and DZ is $0.3 \mathrm{~mm}$, the wear rate is greater after micro cold pressing than without micro cold pressing regardless of the feed times in $\mathrm{Z}$ direction when $\mathrm{DZ}$ is $0.3 \mathrm{~mm}$. 


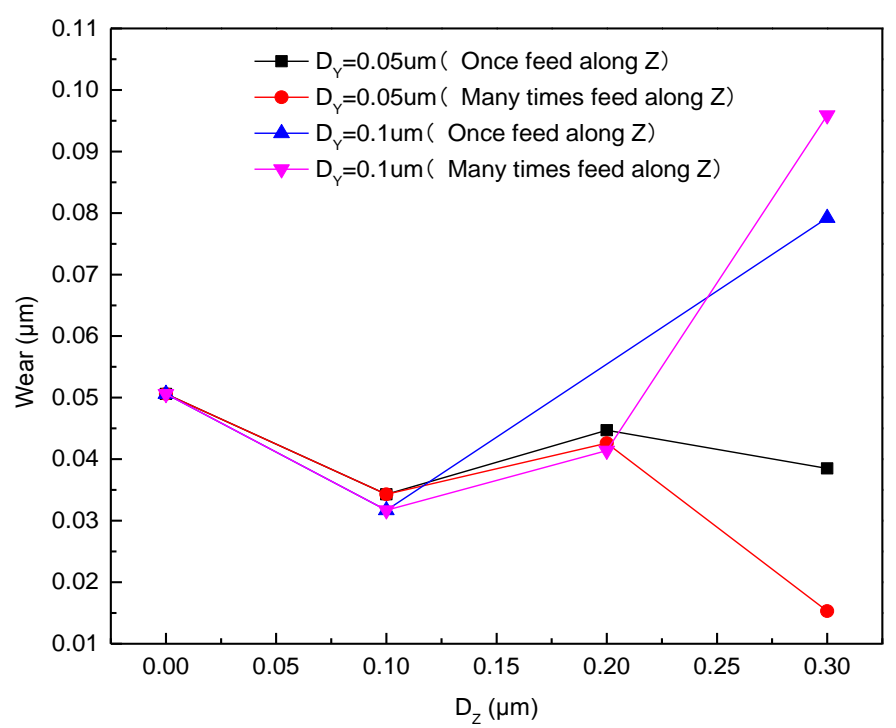

Figure 10. The Relation between Wear Rate and DZ

A comprehensive analysis of Figure 5 and table 4 demonstrates that although No.3 is superior to No.6 in terms of surface roughness and hardness, but the grooved scar in No.6 is more distinct than that in No.3. In addition, the sectional height amplitude of No.6 is greater than that of No.3 because the former is more advantageous for storing abrasive dust and reducing abrasive wear. Hence, the wear rate of No.6 is smaller than that of No.3. The wear rates of No.9 and No.7 is greater than No.0, because grooved scar of No.9 is wider and deeper which leads to its weakness in both number and size of peaks. During friction, oil films between peaks are more likely to be pierced and have a vulnerable stability. Moreover, metal directly contacts with each other when the oil film disappears so that a greater adhesion force is generated and wear rate increases [14-15]. The weakness of surface peaks results in high contact pressure when friction occurs, which significantly increases plastic deformation and wear rate. Grooves of large size appear in the smooth areas of No.7 specimen surface. Therefore, the peaks are far away from each other, which lead to instable friction where sudden changes in pressure often come into being at peaks or valleys and causes great impact and increased wear rate.

Above all, a reasonable control of surface roughness, hardness and surface morphology by controlling DY and DZ can reduce wear rate of specimen.

\section{Conclusion}

(1)Reasonable micro cold pressing can achieve smooth specimen surface. Micro cold pressing causes work hardening, which increases hardness and quality of specimen surface. After micro cold pressing, hardness increases from 0.11 to 0.099 , with surface roughness reduced from $5.496 \mu \mathrm{mto} 1.871 \mu \mathrm{m}$.

(2) Micro cold pressing results in grooved surface morphology with certain depth. The distribution of grooves are related to feed in $\mathrm{Y}$ and $\mathrm{Z}$ direction, denoted by DY and DZ. When DZ is fixed, depth of groove is smaller when DY is $0.05 \mathrm{~mm}$ than that when DY is $0.1 \mathrm{~mm}$. Under fixed DY, the depth of groove increases with the increase of DZ.

(3)A reasonable control of surface roughness, hardness and morphology by controlling DY and DZ can effectively decrease friction coefficient by $10 \%$ at most.

(4)A reasonable control of surface roughness, hardness and morphology by controlling DY and DZ can effectively decrease wear rate by $69.76 \%$ at most. 


\section{Acknowledgment}

The authors would like to express thanks to those who helped in the research work and the preparation of this paper. This work was supported by the National Natural Science Foundation of China (No. 51275543) and Science Fund Project; Project (2012ZX04010-081) supported by the Special Funds for Major Projects of China's Ministry of Science \& Technology.

\section{References}

[1] "China die and mould industry association.12th five year automobile mold development trend" Die \& mould industry, vol.42, no. 02, (2012), pp. 76-77.

[2] M. Nakano, A. Korenaga and A. Korenaga, "Applying micro-texture to cast iron surfaces to reduce the friction coefficient under lubricated conditions", Tribol Letter, vol.37, no. 28, (2007), pp.131137.

[3] Y.- H. Fu, C.- D. Li and X. Hu, "Study on friction and wear properties of the laser textured mold surface with m icro-convex", Tribology, vol.38, no. 05, (2009), pp. 475-480.

[4] Y. Li, X. Liu, Q. Wang and K. Liu, "Effect of laser textured surfaces on frictional property in line contact. Tribology”, vol.33, no. 04, (2013), pp. 349-355.

[5] S. Wen and P. Huang, "Tribology principle. Tsinghua University press", (2002).

[6] Z. Cui and Y. Qin, "Principles of metal science and heat treatment", Harbin Institute of Technology press, (2010).

[7] W. Zhuang and X. Liu, "Study on the impact of working hardness characteristic on the mechanical performance of clinching joint. Automobile Technology", vol.33, no. 11, (2011), pp. 52-56

[8] Li Yao. Metal plastic forming principle. Machinery Industry Press, (2004).

[9] Yin Bifeng, Qian Yanqiang, Dong Feilu, Liu Shengji, Fu Yonghong. Simulative and experimental research on tribological property of micro-groove typed textures. Lubrication engineering.Vol.37, No. 12, p.9-13. (2012)

[10] Yu Haiwu, Wang Xiaolei, Sun Zao, Yuan Sihuan. Theoretical Analysis on Hydrodynamic Lubrication of Cylinder Micro-dimple Surface Texture. Journal of Nanjing University of Aeronautics \& Astronautics.Vol.42, No. 02, p. 209-213. (2010)

[11] Cordier Robert C, Crampon J, Foct J. Surface alloying of iron by laser melting: Micro structure and mechanical properties. Surface Engineering.Vol.14, No. 05, p. 381 -385. (1998)

[12] Meng Hua, Guang-Neng Dong, Hui Zhang John K.L. Ho, Fu-choi Chow .The wet tribological behaviors of doughnut patterns laser-textured on DF2 tool steel under different loading conditions. Applied Physics A.Vol.111, No. 04, p. 997-1011. (2013)

[13] Haosheng, C. Numerical analysis on effect of regular surface topography in non-newtonian fluid lubrication. Chinese Journal of Mechanical Engineering.Vol.43, No. 08, p. 48-52. (2007)

[14] B. Podgornik, L.M. Vilhena, M. Sedlacek. Effectiveness and design of surface texturing for different lubrication regimes. Meccanica.Vol.23, No. 47, p. 1613-1622. (2012)

[15] Zhiwei Guo, Chengqing Yuan, Xinping Yan. 3D Surface Characterizations of Wear Particles Generated from Lubricated Regular Concave Cylinder Liners. Tribol Letter. Vol.43, No. 55, p. 131142. (2014).

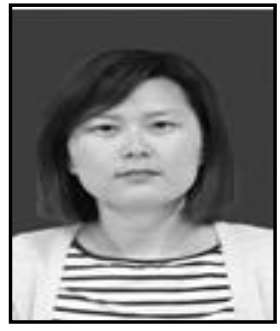

Jing Wang, she was born in January, 1983, Chongqing City, P. R. China Current position, grades: $\mathrm{PhD}$ candidate studying at College of Material Science and Engineering, Chongqing University, China. University studies: She received her B.Sc. in College of Mechanical Engineering from Shandong University of technology in China. She received her M.Sc. from Chongqing Jiaotong University in China. Scientific interest: The wear resistance of die surface. Publications: more than 10 papers published in various journals. Experience: She has teaching experience of 8 years, has completed 3 scientific research projects. 


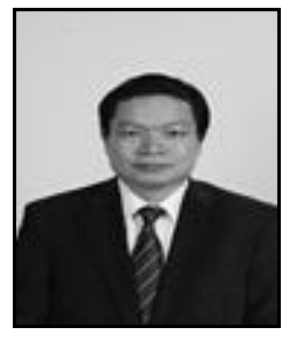

Jie Zhou, he was born in June, 1966, Chongqing City, P. R. China. Current position: Prof of College of Material Science and Engineering, Chongqing University, China. Research Interests:New kinds of processes, technique and equipment of stamping(plates and tubes forming), forging(bulk forming)and some other plastic forming process; Design and optimization of plastic forming technology and die; Technology of prolonging life of dies; Manufacture and remanufacture of plastic forming dies; Design of automated and intelligent equipment of plastic forming process; Application of numerical simulation on plastic forming.

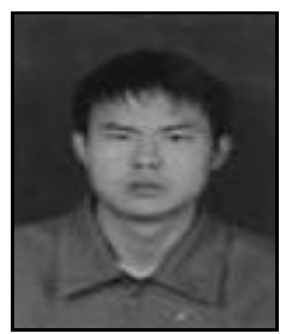

Tiansheng Zhao, he was born in June, 1991, Chongqing City, P. R. China. Current position, grades: Master candidate studying at College of Material Science and Engineering, Chongqing University, China. University studies: He received her B.Sc. in College of Material Science and Engineering from Chongqing University in China.

Scientific interest: The wear resistance of die surface and aluminum alloy forging forming. 
International Journal of Control and Automation Vol. 9, No. 12 (2016) 